\title{
A study on porosity related aspects of cotton knitted fabric with single jersey structure for improved comfort application for garment
}

\begin{abstract}
Knitted fabrics are the preferred structures in athletic wear in which demand for comfort is a key requirement. Heat and liquid sweat generation during athletic \& exercise activities must be transported out and dissipated to the atmosphere. A key property influencing such behaviors is porosity. Two parameters that characterize it are pore size and pore volume. One of the objectives in this research was to come up with models that can predict inter yarn pore size and pore volume for simple weft knitted structures, from fabric particulars, such as courses and Wales, count, yarn size, stitch density, thickness and other geometrical details of the fabric, which characterize the structure. Such a model was developed that was based on the geometry of the unit cell of a single loop. The experimental work in this project involved using a set of 16 knitted fabrics that differ in course count and examining their pore structure and porosity related characteristics. The values of pore size and pore volume were calculated, those of pore size were measured with image analysis, and other parameters. The effects of course count and washing on stitch density, stitch length, fabric thickness and pore size are examined in details.
\end{abstract}

Keywords: knitted fabrics, porosity, air permeability, thickness
Volume 6 Issue 5 - 2020

\author{
Ramratan,' Rohit Kumar, ${ }^{2}$ Suniti Sood ${ }^{3}$ \\ 'Assistant Professor, Department of Textile Engineering, Giani \\ Zail Singh Campus College of Engineering and Technology, \\ Maharaja Ranjit Singh Punjab Technical University, India \\ ${ }^{2}$ Research Scholar, Department of Textile Engineering, Giani Zail \\ Singh Campus College of Engineering and Technology, Maharaja \\ Ranjit Singh Punjab Technical University, India \\ ${ }^{3}$ Associate Professor, Amity Institute of Design, Amity University \\ Gurugram, Manesar, India
}

Correspondence: Ramratan, Assistant Professor, Department of Textile Engineering, Giani Zail Singh Campus College of Engineering and Technology, Maharaja Ranjit Singh Punjab Technical University, Bathinda- 15 I 00 I, Punjab, India, Tel+9l-978I547442, Email ramratan33@gmail.com

Received: August 31, 2020 | Published: October 14, 2020

\section{Introduction}

Comfort is the perceived psychological feeling of a wearer under current conditions of the physical activities and the environment. Knitted fabrics are known for their excellent comfort properties. They possess high extensibility under low load allowing comfortable fit on any part it is pulled onto. ${ }^{1-3}$ As clothing is directly in contact with the human body, it interacts with the skin continuously and dynamically during wear, triggering tactile, thermal and moisture related sensations. ${ }^{4,5}$ The process of transferring heat and moisture in the clothing determines the state of thermo-physiological comfort of the wearer. To achieve the ideal comfort level, heat and sweat generation must be transported out and dissipated to the atmosphere. Porosity is one of the key properties influencing such behavior. ${ }^{6-8}$ While models exist for characterizing pore size and volume in woven and nonwoven materials, not much information exists on how to characterize it in knitted fabrics. The objective of this research is to come up with models that can predict pore size and pore volume from fabric particulars, such as courses and Wales count, yarn size and other geometrical details of the fabric, which characterize the structure. ${ }^{9-12}$ The fabric samples are limited to the simplest of all knit structures, the jersey or plain knitted fabrics, which are commonly found in many apparel applications. Pore volume plays an important role in determining the amount of air trapped in a material or the amount of fluid the structure would hold. ${ }^{13-16}$ Pore size is a parameter that determines the rate at which fluids are imbibed by porous materials. In the construction of the pore size model, the single loop is taken as a unit cell. The plain-knit structure essentially consists of this unit cell repeating itself in both the length and the width directions. ${ }^{17-22}$

In the research work on the review of literature, among other relevant topics, the geometrical structure and parameters of a plain knitted structure. The stitch length model proposed by Peirce is particularly discussed in detail. ${ }^{12}$ His equation for stitch length is utilized in the current study in which pore size is estimated using a model.

Using a controlled set of 16 fabrics that differed in course count, the values of pore size and pore volume are calculated. Pore size is measured with image analysis and other parameters. The role of pore size, pore volume and airpermeability in determining a fabric's fluid holding, and air transport properties are examined and discussed.

\section{Material and methods}

\section{Material}

I have done this research work of the cotton knitted grey fabrics. In this work, I have used combed cotton yarn different type of count 18 $\mathrm{Ne}, 24 \mathrm{Ne}, 30 \mathrm{Ne}$ and $36 \mathrm{Ne}$. I have used this in four types of cotton grey fabrics as shown in Figures 1(a)-(d). The details of the yarns tested are furnished in the Table 1 as follows.

Each of the four types of yarn is used for making single jersey knitted fabric samples on a circular knitting machine with following parameters.

\section{Preparation of fabric sample}

Using each type of yarn, four samples, with four different stitch lengths namely $2.8,3.0,3.2,3.4 \mathrm{~mm}$ were knitted on the same machine under same operating conditions. Therefore, the total no. of samples manufactured is $4 \times 4=16$. Care was taken to maintain yarn input tension at all 48 feeders within range of $10-12 \mathrm{cN}$ as per show Table 2. 


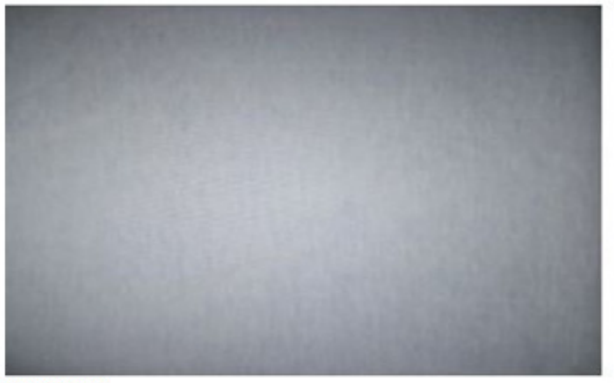

(a) $18 \mathrm{Ne}$

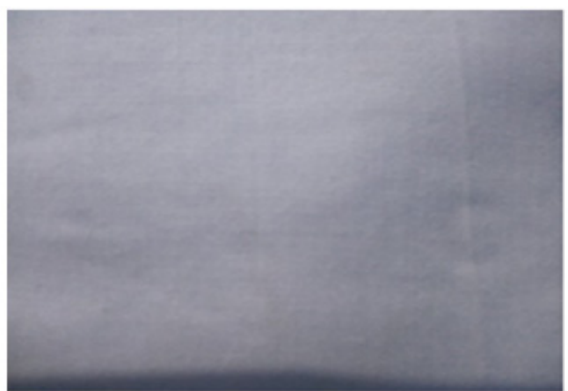

(c) $30 \mathrm{Ne}$

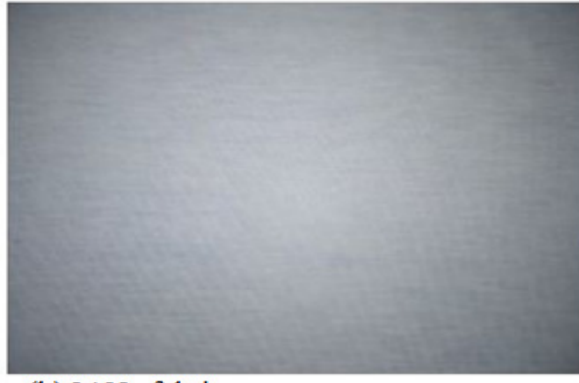

(b) $24 \mathrm{Ne}$ fabrics

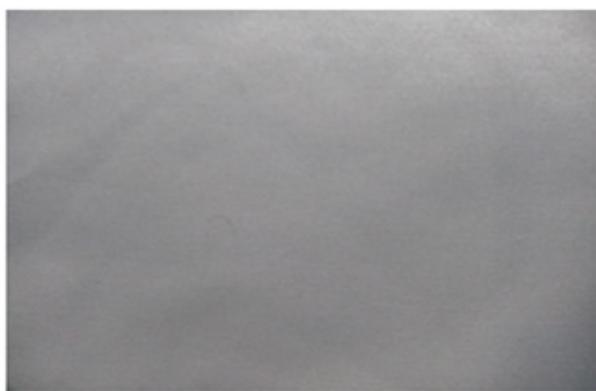

(d) $36 \mathrm{Ne}$

Figure I Cotton knit fabrics.

Table I Detail quality parameters of yarns

\begin{tabular}{llllll}
\hline (Ne) Count & TM & Mean CV (\%) & Tenacity mN/Tex & Elongation (\%) & Unevenness U (\%) \\
\hline \multirow{2}{*}{18} & 3.6 & 1.72 & 177.9 & 4.63 & 8.24 \\
& 3.9 & 1.34 & 141.9 & 4.85 & 8.4 \\
& 4.2 & 1.64 & 230.9 & 5 & 8.28 \\
24 & 3.6 & 2.41 & 154.2 & 4.37 & 9.08 \\
& 3.9 & 2.2 & 188.7 & 4.79 & 8.36 \\
30 & 4.2 & 1.89 & 201.5 & 4.65 & 9.09 \\
& 3.6 & 1.68 & 209.9 & 4.25 & 9.12 \\
36 & 3.9 & 2.13 & 167.3 & 4.14 & 9.43 \\
& 4.2 & 1.41 & 201.2 & 4.64 & 9.7 \\
\hline
\end{tabular}

Table 2 Specification circular knitting machine

\begin{tabular}{ll}
\hline Specification & Single Jersey \\
\hline Number of feeders & 48 \\
Diameter of machine & 24 inches \\
Gauge of machine & $16,20 \& 24$ \\
Positive feed device & Yes \\
Type of creel & Side creel \\
Adjustment for stitch length & Yes \\
Fabric take down system & Adjustable belt \& pulley type \\
\hline
\end{tabular}

\section{Methods}

Wet processing and finishing of fabrics: Wet-processed for used in grey fabric the following recipe in bleaching: Hydrogen peroxide $2 \%$, Caustic soda $-2 \%$, Wetting agent $-0.8 \%$, Anti-crease agent $-0.6 \%$. The temperature was maintained at $90^{\circ} \mathrm{C}$ and the running time was 60 minutes used. Subsequently, the fabrics were given compaction treatment and each fabric sample was separately set in the compaction machine to achieve the nominal finishing targets. All the fabric samples were stitched end to end to ensure that the same chemicals and processing conditions are maintained during wet processing. This will ensure the elimination of any variability on the fabric properties during wet processing. The fabric samples were kept in the lab for 48 hours and then following fabric parameters were measured by following standard procedure. 


\section{Stitch length}

For measuring stitch length, a simple device was fabricated. The description of the device is given below:

Description: A wooden board of dimension 25 "*10" was taken and a $\mathrm{cm}$ scale was fixed on the same. A suitable clip was pasted at the top side of the board. The sample yarn from the fabric was unrevant from the fabric, the fabric being marked for 50 Wales. The marked position on the yarn sample was clipped on the board such that 2 ends of the yarn are clipped forming a loop was measured directly from the scale. If $\mathrm{L}$ is the length of the loop then the length of yarn sample is $2 \mathrm{~L}$. Therefore, the stitch length will be $2 \mathrm{~L} / 50$

\section{GSM}

The weight of the fabric in $\mathrm{g} / \mathrm{m}^{2}$ was measured by cutting the fabric with the help of a round type GSM. cutter and weighing the fabric on electronic balance weight $0.0001 \mathrm{gm}$ accuracy. The area of the fabric was $100 \mathrm{~cm}^{2}$ therefore the weight obtained on the balance was multiplied by 100 to obtain the GSM.

\section{Thickness}

Thickness testing was carried out as per BS EN ISO 9073-2:1995. The thickness of fabric in $\mathrm{mm}$ was measured by the thickness tester at the weight of $20 \mathrm{~g} / \mathrm{f}$. A fabric sample is placed under the weight of $20 \mathrm{~g} / \mathrm{f}$ on a thickness tester and the thickness of fabric sample is displayed on the meter. Here the weight varies from $20 \mathrm{~g} / \mathrm{f}$ to $1000 \mathrm{~g} / \mathrm{f}$.

\section{Porosity (\%)}

The porosity (\%) was determined by formula given by Skinkle 1940: where A- Area of sample $\left(\mathrm{m}^{2}\right), \mathrm{W}$ - Weight of the sample $(\mathrm{g})$, T- thickness of the sample $(\mathrm{cm})$, D- density of fabric $\left(\mathrm{g} / \mathrm{cm}^{3}\right)$ using the equation (i).

$$
P=\frac{100(A T-W / D)}{A T}
$$

\section{Air permeability}

Air permeability was carried out as per ASTM D737-04 using FX 3300 air permeability tester. It measures the air permeability of the fabric sample at 98 atmospheric pressure and suction area $15.07 \mathrm{~cm}^{2}$. A fabric sample is placed on the $\mathrm{m} / \mathrm{c}$ and air permeability is displayed on the monitor screen of the machine. The unit in which fabric sample is measured is $\mathrm{cc} / \mathrm{sec} / \mathrm{cm}^{2}$.

\section{Results and discussion}

This chapter is divided into several sections. The first deals with the single jersey knitted fabric characteristics such as the yarn diameter, stitch length, stitch density, thickness of the fabric. These experiments were performed on the knitted fabric and the following results were obtained which was furnished in Tables 3 \& 4.

Table 3 Fabric parameters as measurement

\begin{tabular}{|c|c|c|c|c|c|c|}
\hline Sample ref. no. & Yarn count $(\mathrm{Ne})$ & Stitch length (mm) & Coarse density $(\mathrm{cm})$ & Wale density $(\mathrm{cm})$ & Thickness (mm) & $\operatorname{GSM}\left(\mathrm{g} / \mathrm{cm}^{2}\right)$ \\
\hline I & 18 & 2.8 & 54 & 34 & 0.634 & 0.0214445 \\
\hline 2 & 18 & 3 & 43 & 28 & 0.61 & 0.0201665 \\
\hline 3 & 18 & 3.2 & 38 & 41 & 0.62 & 0.01878 \\
\hline 4 & 18 & 3.4 & 38 & 32 & 0.58 & 0.0122675 \\
\hline 5 & 24 & 2.8 & 28 & 45 & 0.55 & 0.0170985 \\
\hline 6 & 24 & 3 & 28 & 43 & 0.56 & 0.0161935 \\
\hline 7 & 24 & 3.2 & 42 & 32 & 0.558 & 0.015013 \\
\hline 8 & 24 & 3.4 & 36 & 32 & 0.578 & 0.0142125 \\
\hline 9 & 30 & 2.8 & 31 & 43 & 0.512 & 0.0135465 \\
\hline 10 & 30 & 3 & 31 & 39 & 0.5 & 0.0122675 \\
\hline II & 30 & 3.2 & 38 & 34 & 0.508 & 0.011718 \\
\hline 12 & 30 & 3.4 & 29 & 34 & 0.51 & 0.010842 \\
\hline 13 & 36 & 2.8 & 46 & 34 & 0.458 & 0.0109035 \\
\hline 14 & 36 & 3 & 30 & 37 & 0.448 & 0.0099465 \\
\hline 15 & 36 & 3.2 & 28 & 37 & 0.46 & 0.009143 \\
\hline 16 & 36 & 3.4 & 35 & 34 & 0.458 & 0.0089625 \\
\hline
\end{tabular}


Table 4 Porosity values of air permeability and area (\%) the fabric

\begin{tabular}{llll}
\hline Sample ref. no. & Area (\%) & Porosity $(\%)$ & Air permeability $\left(\mathbf{c c} / \mathbf{s e c} / \mathbf{c m}^{2}\right)$ \\
\hline 1 & 9.817 & 0.9978 & 16.12 \\
2 & 10.215 & 0.99785 & 17.47 \\
3 & 14.688 & 0.99803 & 21.04 \\
4 & 24.4931 & 0.99862 & 26.56 \\
5 & 11.2314 & 0.99798 & 26.54 \\
6 & 11.7709 & 0.99812 & 30.26 \\
7 & 13.7653 & 0.99825 & 44.54 \\
8 & 23.8855 & 0.9984 & 46.92 \\
9 & 22.5413 & 0.99828 & 49.08 \\
10 & 25.722 & 0.9984 & 59.68 \\
11 & 27.1366 & 0.9985 & 68.38 \\
12 & 29.8413 & 0.99861 & 88.28 \\
13 & 18.0133 & 0.99845 & 78.32 \\
14 & 19.9162 & 0.99855 & 91.84 \\
15 & 20.8892 & 0.9987 & 99.62 \\
16 & 29.9018 & 0.99872 & 83.22 \\
\hline
\end{tabular}

Following are the results of effect of different parameters along with porosity which is shown with the help of graphs

\section{Relation between stitch length and porosity at different counts}

This Figure 2 shows the relationship between stitch length and porosity. It shows the effect of stitch length variation porosity. It shows the linear relationship i.e. as the stitch length increases porosity increases.

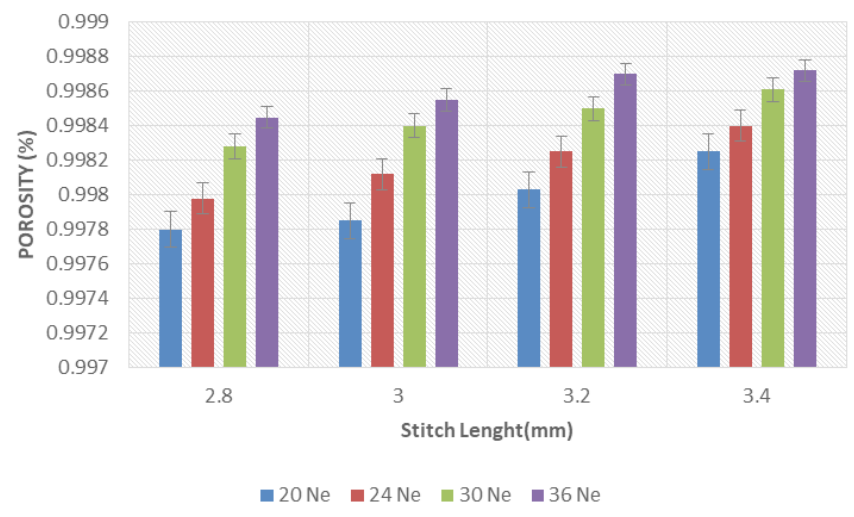

Figure 2 Relation between stitch length and porosity (\%) with different Count.

Relationship between stitch length and air permeability at different counts

This Figure 3 shows the relationship between air permeability and stitch length at different counts. It shows that air permeability varies with stitch length variation. It states that air permeability increases as stitch length increases. It shows the linear relationship between stitch.

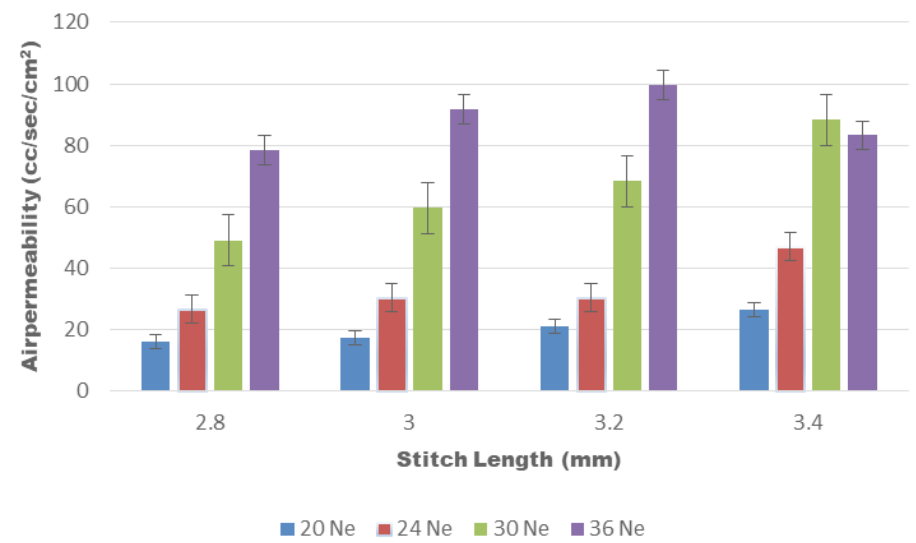

Figure 3 Relation between stitch length and air permeability with different count.

Relationship between stitch length and area \% of porosity at different counts

This Figure 4 shows the relationship between stitch length and area $\%$ age of porosity at different counts. It shows that area $\%$ age of porosity varies with stitch length. It states that as the stitch length increases area $\%$ age of porosity increases. It shows the linear relationship between area $\%$ age of porosity and stitch length. ${ }^{21}$

\section{Relationship between air permeability $\left(\mathrm{cc} / \mathrm{sec} / \mathrm{cm}^{2}\right)$ and porosity}

Air permeability is an important factor in comfort of a fabric as it plays a role in transporting moisture vapor from the skin to outside atmosphere. The assumption is that vapor travels mainly through fabric spaces by diffusion in air from one side of the fabric to the other. The relation between them is shown below Figure 5 . 


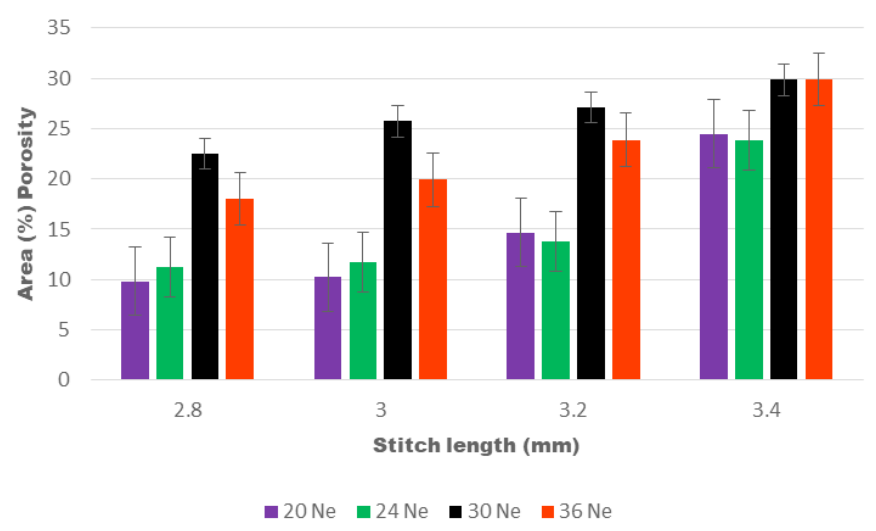

Figure 4 Relation between stitch length and Area (\%) Porosity with different count.

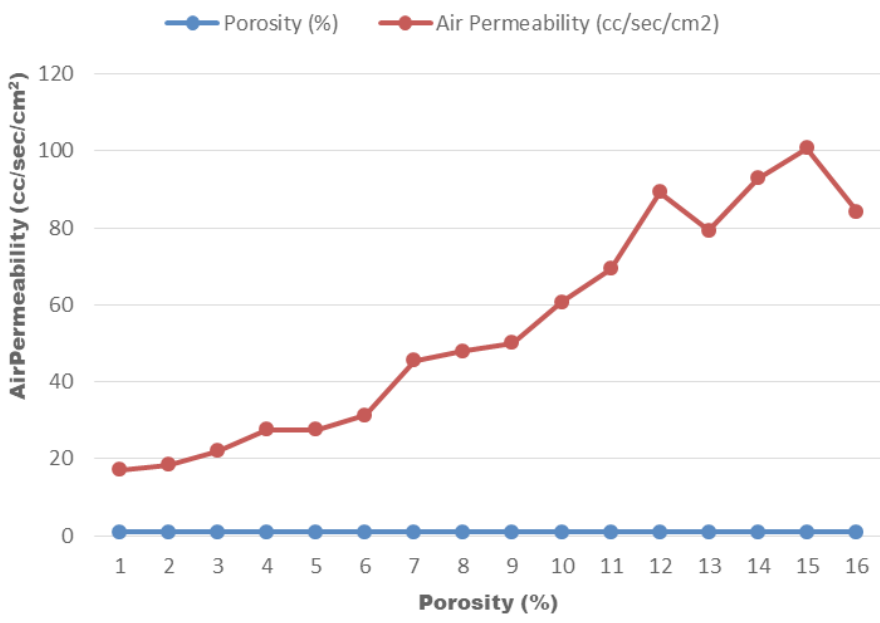

Figure 5 Relationship between air permeability and porosity.

This figure 5 shows the relationship between air permeability and porosity. It shows the effect on the porosity due to air permeability. ${ }^{20}$ Here the graph shown that as the air permeability increases porosity increases and it shows the linear relationship between air permeability and porosity (Table 4).

\section{Relationship between Thickness and porosity is following}

Thickness vs porosity: This Figure 6 , Tables $3 \& 4$ shows the relationship between thickness and porosity. It shows the effect on the porosity due to thickness (mm). It shows as the thickness decreases porosity increases. ${ }^{19}$ It shows the linear relationship between thickness and porosity.

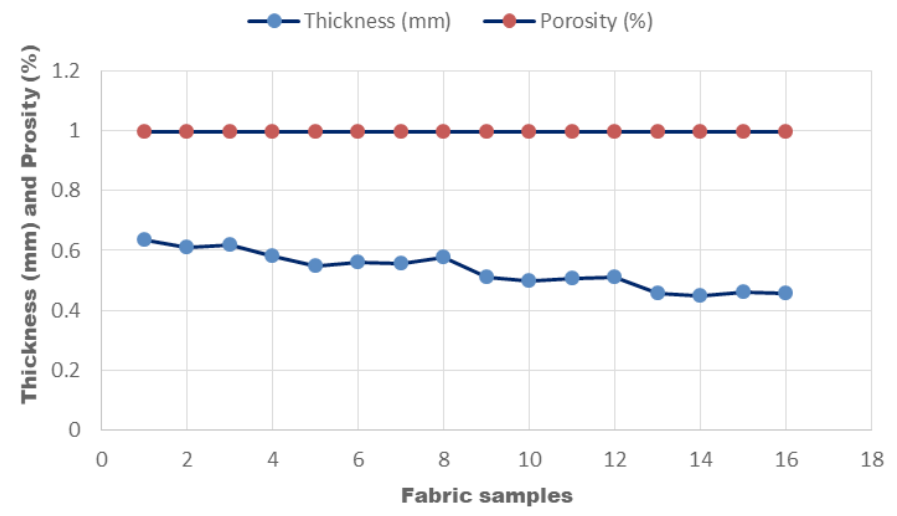

Figure 6 Relationship between thickness and porosity.

\section{Conclusion}

a. The study can provide useful guidelines to instrument developers regarding possible ways to obtain more structurallyrelated pore size parameters. In addition to this main objective, important factors such as fabric construction parameters and fabric state (dry or washed) were also examined.

b. The main conclusion of this study is that there is a noticeable difference between the model-based estimated pore size values and the measured values.

c. The pore size values decreased with increase in course density and they decreased due to increase in stitch density. Stitch density and fabric weight were found to be strongly correlated. As the stitch density increased, fabric weight also increased.

d. Air permeability has direct relationship with pore size. An increase in pore size led to an increase in air permeability. The fabric with the lowest stitch density has the best air permeability. The same fabric also has the best rate of moisture absorption.

\section{Acknowledgments}

The Authors wishes to express their heartfelt gratitude to the authorities of GZSCCET bathinda and NIT Jalandhar to provide the facilities for conducting the required test in their laboratories. Special thanks are also due to the HOD and staff of Textile Engineering Department of Giani Zail Singh Campus College of engineering and technology, Maharaja Ranjit Singh Punjab Technical University, Bathinda 151001, Punjab (India), without whose help this work would not have been.

\section{Funding}

None.

\section{Conflicts of interest}

Authors have declared no conflicts of interest.

\section{References}

1. Munden DL. The geometry and dimensional properties of plain-knit fabrics. The Journal of the Textile Institute. 1959;50 (1):448-471.

2. Gupta BS. The effect of structural factors on the absorbent characteristics of nonwovens. TAPPI Journal. 1988;71(8):147-152.

3. Chu CC, Welch L. Characterization of morphologic and mechanical properties of surgical mesh fabrics. Journal of Biomedical Materials Research. 1985;19(8):903-916.

4. Pourdeyhimi B. Porosity of surgical mesh fabrics- new technology. Journal of Biomedical Materials Research. 1989;23(13):145-152.

5. Guidoin R, King M, Marceau D, et al. Textile arterial prosthesis: Is water Permeability equivalent to porosity. Journal of Biomedical Materials Research. 1987;21(1):65-87.

6. Rollin AL, Denis R, Estaque L, et al. Hydraulic behavior of synthetic Nonwoven filter fabrics. The Canadian Journal of Chemical Engineering. 1982;60(2):226-234.

7. Mary $\mathrm{C}$, Marois $\mathrm{Y}$, King $\mathrm{M}$, et al. In vitro and in vivo studies of a polyester arterial prosthesis with a warp-knitted sharkskin structure. Journal of Biomedical Materials Research. 1987;35(1):459-472.

8. Ma Y, Shishoo R. Permeability characterization of different architectural fabrics. Journal of Composite Materials. 1999;33(8):729-750.

9. Winter mantel E, Mayer J, Blum J, et al. Superstructures scaffolds using. Tissue Engineering Biomaterials. 1996;17(2):83-91. 
10. Algaba I, Riva A. Influence of fiber type and fabric porosity on the UPF of summer fabrics. AATCC Review. 2004;4(1):26-31.

11. Parmar MS, Srivastava SK. An unconventional way to incorporate comfort in knitted fabric. Indian Journal of Fiber \& Textile Research. 1999;24(1):41-44.

12. Peirce FT. Geometrical principles applicable to the design of functional fabrics. Textile Research Journal. 1947;17(1):144-147.

13. Leaf GAV, Glaskin A. The geometry of a plain knitted loop. The Journal of the Textile Institute. 1955;46(1):587-605.

14. Demiroz A, Dias T. A study of the graphical representation of plain-knitted structures Part I: Stitch model for the graphical representation of plainknitted structures. The Journal of the Textile Institute. 2000;91(10):463480 .

15. Doyle PJ. Fundamental aspects of the design of knitted fabrics. The Journal of the Textile Institute. 1953;44(1):561-567.

16. Munden DL. Specification of construction of knitted fabrics. The Journal of the Textile Institute. 1962;53(1):628-631.
17. Booth JE. The geometry of plain weft knitted fabrics. Textile Mathematics, The Textile Institute, Manchester. 1977;3(1):487-499.

18. Shinn WE. An engineering approach to jersey fabric construction. Textile Research Journal. 1955;25(1):270-277.

19. Dias T, Delkumburewatte GB. Changing porosity of knitted structures by changing tightness. Fibres and Polymers. 2008; 9(1):76-79.

20. Ogulata RT, Koç E. A Theoretical model for air permeability of woven fabrics. Association for The Advancement of Modeling \& Simulation Techniques in Enterprises. 2001;70(8):39-48.

21. Ogulata RT. Air permeability of woven fabrics. Journal of Textile and Apparel, Technology and Management. 2006;5(2):1-10.

22. Epps HH, Leonas KK. The relationship between porosity and air permeability of woven textile fabrics. Journal of testing and evaluation, JTEVA. 1997;25(1):108-113. 